\title{
MIRADOR DE ILUSIONES. CUADERNO DE CINE PARA LA EDUCACIÓN ESCOLAR (2020)
}

Jorge Eslava. Universidad de Lima, Fondo Editorial.

doi: https://doi.org/10.26439/en.lineas.generales2021.n5.5425

\author{
Alejandro Núñez Alberca \\ Universidad de Lima
}

Aunque suene paradójico, existen profesiones que corren el riesgo de ser impracticables. Al menos esa fue la opinión de Freud respecto a gobernar, curar y educar: el mandatario no podrá gobernar si el pueblo no se lo permite, del mismo modo que el enfermo no será curado si estorba o impide la función del médico. En el caso de la educación, la historia parece ser la misma. Si el estudiante no permite que le enseñen o no está dispuesto a atender, el profesor difícilmente podrá llevar a cabo su clase. He ahí una función del docente que muchas veces se pasa por alto: hacer que el estudiante se interese por la materia, que tenga el deseo de aprender.

El libro Mirador de ilusiones asume esta labor con una pasión genuina por la enseñanza y, sobre todo, con la urgencia de convencer a otros del valor artístico del séptimo arte. Pecaríamos de ingenuos si esperamos encontrarnos con otro de los tantos manuales de lenguaje audiovisual que abundan en el mercado y en internet. La misión de Jorge Eslava es muy distinta. Ante todo, despertarnos del viejo prejuicio que empareja el visionado de una película en el aula con una hora perdida o tiempo libre, idea con la cual (me temo) muchos de nosotros hemos crecido.

Apostar por el cine es ante todo creer en su fuerza. Después de todo, hay una razón por la cual los productos culturales no se comercializan del mismo modo que una lata de atún o un producto para el cabello. Como todo arte, el cine nos habla y pide de nosotros una respuesta a la altura del desafío.

Claro está, no es un diálogo como el que puedo tener con mi mejor amigo o mi padre. Nadie se va a salir de la pantalla y dirigirse a mí como en La rosa púrpura del Cairo, de Woody Allen. Es una conversación más sutil la que se espera que mantengamos, y una que puede llevarse a cabo incluso sin ser conscientes de ella. Así, no solo nuestro imaginario queda alterado para siempre, también lo hace nuestra sensibilidad.

Pero ¿qué ocurre cuando este diálogo se vuelve evidente y nos hallamos menos solos que antes? ¿Qué hacer cuando una película nos hace sentir algo inédito, para lo cual carecemos por completo de palabras, pero nuestro compañero de al lado o nuestro docente sí las conoce? 
En parte, esta es la apuesta del Mirador, que esos momentos sean posibles dentro de los confines de un salón de clase. En lugar de estar sujetos a una metodología escolástica sobre el cine, es preferible atreverse y construir los primeros bosquejos de una experiencia artística: aprender a ver y sentir un filme, discutirlo y comunicar finamente nuestras ideas. He ahí otro de los méritos del libro: insistir en la experiencia del cine como arte colectivo tanto en su producción como en su recepción, en una época en que este tipo de espacios corre el riesgo de extinguirse.

Es algo que se deja ver en la estructura misma del trabajo, la plurivocidad que le sirve de guía. Para fundamentar sus premisas, Eslava no solo recurre a su amplísima experiencia como docente o a su conocimiento enciclopédico sobre cine. Se aproxima a conversar con educadores, investigadores, realizadores y académicos de la talla de Fernando Ruiz Vallejos o Desiderio Blanco. Echa mano de biografías de artistas, clásicos de la literatura universal y la teoría psicoanalítica. El dialogismo no solo es la gran apuesta pedagógica del Mirador, sino que se encuentra en el corazón mismo de su discurso. Es expresión al mismo tiempo que contenido.

Como todo diálogo, los participantes han de estar listos para el encuentro. Es entonces una labor formativa doble: preparar al estudiante y al docente para que sepa guiar la discusión del filme, algo que solo se logra dedicándole el tiempo suficiente al visionado, nutriendo la memoria íntima de todo lo que se ve, piensa y experimenta.

Así, el Mirador nos invita al juego y pone a nuestra disposición una enciclopedia de términos y obras cinematográficas que trascienden las épocas, los géneros y los países. En muy pocos sitios encontraremos un filme de los hermanos Dardenne a unas cuantas páginas de un título de David Lynch o un póster de Escuela de rock, así como una sobria explicación de esta coincidencia tan aparentemente insólita.

Cada capítulo cierra con una "Función continuada", un recuento de más de veinte películas con las que Eslava nos invita a poner en práctica su propuesta. Cuidémonos de tomar esto como un simple listado de términos o de títulos. Los lectores del Mirador deben ver en cada reseña un ejercicio en potencia, uno que funciona mejor cuando se trabaja en equipo. Al final de cada una, el docente encontrará un comentario e interrogantes que marcan el inicio de un ejercicio crítico sobre la película, pero que no dudan en indagar sobre cuestiones más amplias: la infancia, la educación, la familia, la delincuencia, los abusos de poder, etcétera. Paralelamente al entretenimiento y a la expresividad que lo caracteriza, el cine demuestra su valía como documento social, capaz de reactivar deseos, temores y memorias.

Y para orientar esta sesión el docente tiene que prepararse, hacerse un experto en la película que tan humildemente ha visto y que ahora viene a ofrecer a su estudiante. Tiene que, en primer lugar, convertirse en un cómplice del Mirador, unirse a él (la 
etimología de complicidad significa literalmente eso) y acto seguido entusiasmarse por la película que ha elegido, verla varias veces, leer sobre ella, discutirla en privado antes de mostrar su emoción a alguien más. Es verdad que uno nunca termina de aprender e igualmente cierto es que lo que consumimos ante la pantalla nos forma en conocimientos, pero también en sensibilidades. Es una labor complicada, ardua, pero solo se vuelve imposible si la persona a cargo deja de creer en lo que predica. He ahí el porqué de llamarse cómplice del libro y no solamente su lector.

Quien haya tenido un acercamiento con la enseñanza o el cine entenderá el inmenso valor del trabajo de Eslava, así como la nobleza de su misión. El Mirador no pretende hacer un recorrido exhaustivo de la historia del cine, mucho menos profundizar en teoría cinematográfica o teoría de géneros audiovisuales (solo un par de capítulos están dedicados a esto), pero sí apunta a despertar en su lector un interés primigenio desde el cual transitar por estas vías. Las artes suelen ser terrenos vertiginosos, confusos y con frecuencia enigmáticos. Pero, digo yo, ¿qué mejor forma existe para señalar la promesa de una aventura? 